\title{
OBJETOS EDUCACIONAIS DIGITAIS NA EAD E EDUCAÇÃO INCLUSIVA NA ÁREA DE FÍSICA
}

Diana E. Tuyarot - DEC/IFSUDESTEMG, Juiz de Fora, diana.tuyarot@ifsudestemg.edu.br Rita de Cassia Tesseroli -DINF/UFPR, Curitiba, tesserolirita@gmail.com

\section{Resumo}

A proposta deste trabalho é a análise e caracterização de Objetos de Aprendizagem (OA), para o ensino de física. É realizada também uma sondagem de acessibilidade para o uso dos OA por pessoas surdas. O trabalho está embasado na Teoria da Aprendizagem Significativa Crítica e nos conceitos de mediação. São definidos os facilitadores para promover o ensino e aprendizagem e o papel central ou secundário dos OA, dependendo da proposta a ser desenvolvida pelo educador. É estabelecido o que configura-se em Modelo na área de física e sua relação com os OA. É apresentado o conceito de interação e interatividade e a relação destes conceitos com os OA e questiona-se como poderá se ensinar física mediante o uso de OA incluindo os mesmos em AVAs e trazer acessibilidade para a pessoa surda. É realizado uma classificação de vídeos e simulações voltadas para o ensino das Leis de Newton disponibilizados na web e dessa amostragem é encontrado que só $35 \%$ dos OA poderiam ser utilizados em contexto de inclusão, numa situação formal de ensino, sem ter que realizar nenhuma adaptação.

Palavras-chave objeto de aprendizagem, inclusão, ensino de física, AVA

\section{OBJECTS EDUCATIONAL DIGITAL IN ODL AND INCLUSIVE EDUCATION IN PHYSICS AREA}

\begin{abstract}
The purpose of this work is the analysis and characterization of learning objects (OA), for physics teaching. also it is conducted an accessibility survey for the use of OA for deaf people. The work is based in the Theory of Meaningful Learning Review and the concepts of mediation. Facilitators are set to promote the teaching and learning and the central or secondary role of OA, depending on the proposal to be developed by the educator. It is established that sets in model in the field of physics and its relationship with OA. It presented the concept of interaction and interactivity and the relationship of these concepts with OA and wonders how can teach physics through the use of OA including the same in VLEs and bring accessibility to the deaf person. It held a rating of videos and directed simulations for teaching Newton's Laws available on the web and this sample is found that only $35 \%$ of OA could be used in the context of inclusion in a formal teaching situation, without having to perform any adaptation.
\end{abstract}

Keywords object of learning, inclusion, physical education, AVA

\section{Introdução}

Para falar de Objetos de Aprendizagem necessariamente deve-se falar de mediação, assim o objeto será o mediador entre o que se pretende ensinar e o aprendiz. O Objeto de Aprendizagem é uma construção realizada com um sentido e objetivo pré-determinado que é utilizar o mesmo como uma ferramenta para transmitir um conhecimento. Assim, Objeto de Aprendizagem será uma imagem, um vídeo, simulação, modelo, ou outro elemento que possa ser utilizado e reutilizado, que tenha um objetivo educacional definido e esteja 
disponível, dentre outras qualidades. Já falar em mediação traz um conceito mais complexo e vinculado com as raízes da criação do conhecimento. Mediação traz o conceito de signo, parafraseando a Lúcia Santaella, (SANTAELLA, 2007)

"São os signos, as linguagens que abrem, à sua maneira, as portas de acesso ao que chamamos de realidade. No coração, no âmago, no cerne de quaisquer mediações - culturais, tecnológicas, midiáticas - está a linguagem, é justamente a linguagem, camada processual mediadora, que revela, vela, desvela para nós o mundo, é o que nos constitui como humanos"

Vigotsky define a mediação como uma parte importante na aquisição dos conhecimentos já que "a relação do homem com o mundo não é uma relação direta, mas uma relação mediada" (KHOL, 1995).

Quando se fala de inclusão e se tenta definir o conceito sensorial, este delimitado aqui exclusivamente ao conceito de surdez, encontra-se diversos estágios ou degraus de perda auditiva, surgindo com isso vários interrogantes em relação com a construção do conhecimento realizado pelo sujeito (LIMA, 2010). Estas pessoas desenvolvem uma forma de comunicação relacionada com o meio onde vivem. Quando se fala de Objeto de Aprendizagem (OA), e se tenta utilizar o mesmo num contexto de inclusão o OA deve estar construído, desenhado, pensado intencionalmente para essa situação. A proposta é identificar dentre os OA disponíveis alguns daqueles voltados para a área de física e a partir desse levantamento:

- observar o nível de conhecimento para utilização do OA que tem que ter a pessoa.

- observar se o OA está adequado ao conceito da física que pretende ser ensinado.

- estudar se o objeto educacional pode ser utilizado por pessoas com necessidades especiais.

\section{Fundamentação teórica}

\subsection{Aprendizagem Significativa Crítica}

Este trabalho tem embasamento nas teorias de aprendizagem significativa crítica (MOREIRA, 2010) que vem a resignificar o trabalho de Ausubel e Novak, e também apresentar nova apreciação do ensino subversivo de Postman e Weingartner. Neste sentido a proposta é que o ensino a aprendizagem sejam nas condições da teoria, respeitando o conhecimento prévio do estudante, apresentado facilitadores e incentivando ao aluno para o questionamento e a participação ativa.

\subsection{Objetos de aprendizagem e o ensino de física}

O Objeto de Aprendizagem será uma imagem, um vídeo, simulação, modelo, ou outro elemento que possa ser utilizado e reutilizado, que tenha um objetivo educacional definido e esteja disponível dentre outras qualidades. Quando se fala de OA, e se tenta utilizar o mesmo num contexto de inclusão o OA deve estar construído, desenhado, pensado intencionalmente para essa situação.

Os componentes fundamentais de um OA são apresentados na Figura 1. Dessa forma, OA são reutilizáveis, tem objetivo e conteúdo, são multimídia, são ferramentas de aprendizagem, desenvolvem pensamento crítico, oferecem retorno, auxiliam a compreensão de conceitos escolhidos pelo professor que deve conhecer formas de uso e esses conceitos 
estão ancorados em conceitos prévios e aprendizagem significativa. Este mapa não esgota a definição de OA, podendo abranger outros conceitos relacionados com os mesmos.

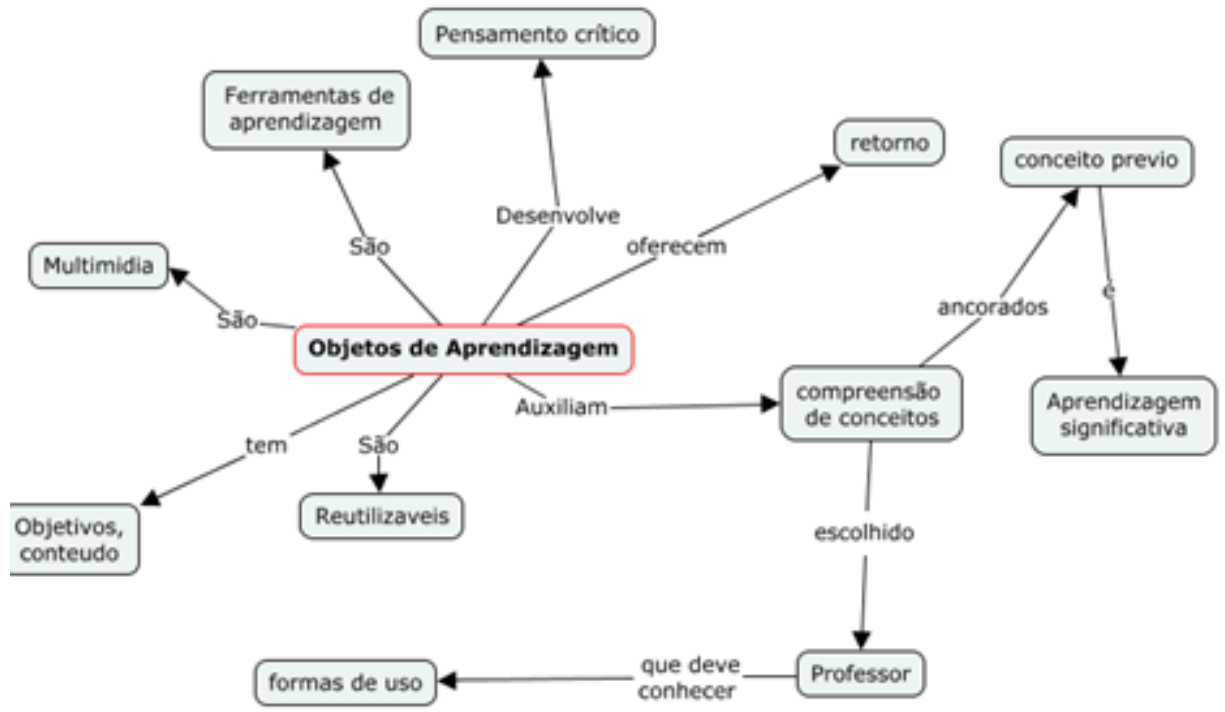

Figura 1: Mapa conceitual Objetos de Aprendizagem construído utilizando (WINCMAP TOOLS, 2016).

Arantes, sugere que seria necessário avaliar a eficácia dos OA verificando se contribuem para o aprendizado. Os autores analisam as simulações do Phet $^{1}$, projeto da Universidade de Colorado, voltados para essa área e propõem várias estratégias de uso. $\mathrm{O}$ Phet tem simulações interativas de uso livre para diversas áreas de conhecimento e estão desenvolvendo outras com acessibilidade. (ARANTES, 2010)

Araujo apresenta uma compilação para facilitar o uso pelo professor dos OA (ARAUJO, 2009). O trabalho traz uma seleção útil das mídias e ferramentas para serem utilizadas pelo professor, mas os recursos e estratégias apresentadas não focalizam a inclusão de pessoas com necessidades especiais.

Os autores ministram um curso online voltado para professores em atividades e com objetivo de utilização das TICs nas salas de aula. São apresentados exemplos de planos de aulas, uma crítica acerca dos OA, e links de ferramentas e materiais de apoio. Os autores alertam para avaliar o conteúdo do OA e realizar uma escolha crítica do mesmo.

É conhecido que o EAD e suas plataformas de ensino são voltados para a instrução de pessoas adultas, em todos os níveis de ensino. Uma das ferramentas que podem ser incluídas nas plataformas são os OA já que estes, nas suas mais variadas formas, constituem o recurso de auxilio estreitamente relacionado com os softwares e as tecnologias disponíveis para facilitar a aprendizagem facilitando as estratégias de ensino.

Os alunos da escola regular de ensino fundamental e médio poderão, no entanto, fazer uso do OA disponibilizados, seja para uso na aula presencial ou para resolução de tarefas

${ }^{1} \mathrm{O}$ Phet é um projeto ideado e desenvolvido pelo Prof Carl Weiman. premio Nobel de Física com discentes e colaboradores da Universidade de Colorado. (https://phet.colorado.edu/pt_BR/accessibility/research) e (https://drive.google.com/file/d/0B44Uycdx6JGdR3V2ZkVjN2pBNU0/view ). 
solicitadas para casa. Numa educação inclusiva deverá ser levado em conta a possibilidade de as pessoas com necessidades especiais virem a fazer uso dos OA.

No contexto da aprendizagem significativa de ciências o trabalho de Araujo (ARAUJO, 2012) apresenta o seguinte questionamento para alicerçar os conceitos de "modelo" na área de física: "como atividades de ensino voltadas para os processos de elaboração e análise de modelos científicos podem contribuir para propiciar aos alunos uma aprendizagem significativa dos conteúdos e também uma visão mais adequada da práxis científica atual?" Os autores explicam a potencialidade da modelagem e observam que apesar da proliferação dos Objetos de Aprendizagem voltados para o ensino de física existe uma subutilização dos mesmos.

O referencial epistemológico utilizado pelos autores define o que é modelo nas palavras dos mesmos,

"Para avaliar a concordância dos resultados teóricos com os experimentais, é preciso inserir modelos conceituais de referentes reais - que por si só são estéreis - em sua estrutura. Essa inserção fornecerá uma teoria específica sobre o "recorte" da realidade que se pretende representar, um modelo teórico, e somente seus resultados é que serão passíveis de comparação com os resultados empíricos." (ARAUJO, 2012)

Segundo Bunge (1974 apud ARAUJO, 2012) deve-se agregar ao modelo a transitoriedade, já que os modelos podem ser modificados e isto é inerente ao conhecimento cientifico. Araújo faz considerações do que é entendido por modelo no ensino e aprendizagem de física. Relaciona o modelo com o acesso ao mesmo que os estudantes poderão ter com a inclusão do computador. A partir desse fato evidenciam a potencialidade que tem os modelos computacionais tais como modelagem e simulação.

Dentro desse contexto, o autor descreve o propósito do modelo computacional e que para "o bom desenvolvimento das tarefas didáticas associadas ao modelo computacional dependerá diretamente da qualidade das perguntas formuladas. Quanto mais o aluno tiver que interagir (inteligentemente), avaliar e refletir para respondê-las, respeitando seus limites cognitivos, melhor."

Esta interatividade, entendida como a possibilidade que o aluno tem de modificar o modelo e/ou a simulação, vem a ser o centro que relaciona o aluno e o conhecimento (ARAUJO, 2008). A interatividade pode ser percebida, também, como interação da pessoa com/através de uma máquina ou através das TICs ou derivada da interação entre duas pessoas (PRIMO, 1999).

Foram apresentados, nesta seção, os OA como uma ferramenta disponível para sua utilização no ensino e aprendizagem de física. Os modelos físicos criados para explicar um fenômeno são potencializados mediante a utilização do computador que possibilita uma interação entre o aluno e o conhecimento que se pretende passar. Para o desenvolvimento dos modelos computacionais podem ser utilizadas várias estratégias dependendo dos objetivos didáticos.

\subsection{Ensino de física e pessoas com necessidades especiais.}

Na educação a distância, em geral, o uso de OA apresenta-se com a necessidade de definir como será a interação entre os seus usuários e traz situações que precisam atenção, 
por exemplo, aparecem inquietações no relacionado com a maneira em que se dará a interação num contexto de inclusão de pessoas com necessidades especiais.

Nas aulas presenciais o professor interage diretamente com o aluno face a face. Através dessa atividade síncrona é possível mudar o enfoque do conteúdo de acordo com o retorno dos alunos. No EAD o professor conta com o recursos computacionais para auxiliar o aluno a construir um conhecimento. No entanto, por tratar-se de uma atividade desenvolvida ora síncrona, ora assíncrona, o professor terá o retorno dos alunos somente após testes ou atividades especificas dificultando a possível remediação.

No caso especifico de alunos com necessidades especiais no EAD o professor poderá desenvolver atividade especifica voltada para essa necessidade do aluno, mas em ocasiões o mesmo poderá não ter a interação totalmente síncrona necessária para poder definir como deveria ser essa atividade. Por exemplo, no caso de surdez a construção do conhecimento está estreitamente vinculada com a forma como o sujeito desenvolve o saber linguístico, o surdo tem uma forma especifica de comunicação, através da LIBRAS, e existem vários conceitos físicos que não possuem sinal especifico, no caso presencial o professor preenche essa carência utilizando outras opções, no entanto no EAD não haverá essa oportunidade. Daí o fato do OA ter que ser pensado com acessibilidade pois será o apoio para o aluno especifico que virá a suprir a carência de interação professor-aluno em tempo real.

Em relação com o papel do computador e a pessoa com deficiência Valente afirma, (VALENTE, 1991, p 7), conforme citado por (BARDY, 2013), "o computador pode ser uma ferramenta de aprendizado, como pode ser também a ferramenta com a qual a criança com deficiência física pode interagir com o mundo das pessoas e dos objetos".

Na perspectiva de utilização de OA o modelo pedagógico será um fator que deve ser observado. Sarabando escreve, alertando, que a eficácia das simulações está estreitamente vinculada com a pedagogia utilizada para sua implementação, a falha nisso pode explicar alguns resultados negativos. $\mathrm{O}$ fato de somente providenciar o acesso ao computador e software sem cuidado, atenção e suporte ao aprendizado além de modelos de ensino não traz resultado desejado. (SARABANDO, 2014).

A pesquisa de (SILVA, 2008) avalia a usabilidade dos OA utilizados como ferramentas para o ensino de física em geral. A conclusão dos autores é que "a maioria dos OA não apresenta uma fundamentação pedagógica explícita de seus ambientes, o que consequentemente acarreta desvios na eficiência do processo ensino e aprendizagem. ”.

Estudar o modelo pedagógico utilizado configura-se numa questão que poderá também ser levantada se o objetivo for analisar se o OA está adequado ao conceito da física, que pretende ser ensinado, e a forma como será abordado. Devido ao crescente desenvolvimento dos $\mathrm{OA}$ a equipe de ensino deve frequentemente realizar essa análise.

Em relação aos alunos com necessidades especiais pode-se acrescentar que os OA para serem utilizados pelos alunos devem levar em conta qual a necessidade do estudante, facilitando o acesso pelos mesmos. Como mencionado na introdução o propósito deste trabalho será realizar uma análise da acessibilidade do OA voltados para o ensino de física. Para pessoas com necessidades especiais, o OA deverá ser intencionalmente desenhado para esse objetivo.

\section{Metodologia}

O método utilizado para a pesquisa é a pesquisa de campo secundária para a qual utilizar-se-ão resultados de dados já coletados assim como trabalhos em andamento na área. 
Trata-se de uma pesquisa qualitativa cujo objetivo é a análise dos OA, voltados para o ensino de física, numa perspectiva de inclusão, focalizando especificamente a pessoa com necessidades especiais auditivas. A técnica a ser utilizada será a análise documental.

No caso específico de ensino-aprendizagem a distância ou EAD além de observar qual OA é utilizado será observado como este poderá ser implementado na plataforma. As definições de interação e interatividade poderão ajudar a entender o percurso a seguir. A Interação é a relação entre os indivíduos e a modificação que surge a partir dela e, Interatividade, está vinculada com a forma de como irá acontecer a interação e para o qual é considerado que o receptor nunca é totalmente passivo.

A seleção de ferramentas deve ser realizada por uma equipe preparada, está trabalhando em conjunto e intencionadamente, levando em conta os quatro estilos de aprendizagem (VERASZTO, 2011). Essas ferramentas de mídia que terão que acompanhar também o perfil de estudante, levando em conta que o espaço do professor é diferente do aluno assim como a relação destes com os recursos. Haverá pessoas mais voltadas para o gráfico, outras para o escrito e outras modalidades de recursos.

Também deverá ser levado em conta as possibilidades dos alunos participarem de forma síncrona ou assíncrona. É através do diálogo (interação) que pode ser entendido qual recurso (interatividade) poderá ser voltado para determinado aluno (perfil com um estilo de aprendizagem). O EAD pela sua característica precisa de um médio para acontecer. Assim o Dialogo é a forma de interação mais efetiva, mediado no EAD pelas tecnologias daí a importância da seleção das ferramentas.

Com objetivo de informar ao professor ou futuro profissional acerca da tecnologia disponível para um tema especifico a partir da pesquisa documental poderá ser apresentada uma análise da disponibilidade, necessidade, nível escolar focalizado, nível de conhecimento da tecnologia e conceito a ser ensinado.

\subsection{Caracterização do objeto de pesquisa}

Nesta seção ir-se-á identificar alguns dos OA disponíveis voltados para a área de física e analisar a acessibilidade, dentre a variedade de OA em particular serão apresentados vídeos, animações e/ou simulações. Os OA serão escolhidos no site do MEC por tratar-se de uma base completa disponibilizada para uso aberto. O tema escolhido é a Leis de Newton por tratar-se de um conteúdo presente em todos os níveis de ensino de física.

Encontra-se em Silva (SILVA, 2008) a referência aos parâmetros de avaliação de um OA, o "checklist" apresentado com 20 itens não tem acessibilidade como um deles (http://www.uel.br/seed/nte/analisedesoftwares.html). O que configura uma carência nessa pesquisa é a não avaliação do item acessibilidade. Isto pode ser atribuído a que na época a acessibilidade ainda não era uma preocupação central no desenvolvimento de OA. Este fato corroborado no link do Phet que relaciona pesquisas com esse objetivo a partir de 2015. (Phet, 2015)

Segundo Bardy e colaboradores (BARDY, 2007), "Os Objetos de Aprendizagem (OA) são ferramentas auxiliares no processo de ensino e aprendizagem de conceitos disciplinares, disponíveis na internet." (pg. 95). No contexto citado acima, dependendo da classe de objeto terá uma estrutura mais ou menos passível de interagir e auxiliar esse conhecimento.

\section{Apresentação e Discussão dos Dados}

V. $14 \mathrm{~N}^{\mathrm{o}} 2$, dezembro, 2016 
Nas próximas seções serão apresentados os resultados da busca de vídeos e simulações/animações voltadas para o ensino das Leis de Newton. Serão analisados numa perspectiva de inclusão além das características básicas esperadas para um OA. Tabelas com conceitos e com resultados acerca da adequação para uso por pessoa surda são organizadas de forma de mostrar qualitativa e quantitativamente essas adequações. É realizada uma breve análise estatística para conferir o tamanho da amostra e o erro associado.

\subsection{Videos}

O Vídeo é uma construção baseada em imagens (fotogramas) cuja sucessão produz a ilusão de movimento. Observar um vídeo mudo poderá representar para a pessoa ouvinte um exemplo da situação da pessoa surda. Tentar descrever o que se passa no vídeo poderá ser um exercício para incluir uma pessoa cega.

Realizada uma busca de vídeos relacionados com Física, no site do $\mathrm{mec}^{2}$, em geral obtemos uma resposta com 524 para o Ensino Médio e 201 para o Superior. Um refinamento na busca para "vídeo+física+leis de Newton" devolve uma página com 10 itens (Tabela 1), esses vídeos serão numerados 1 ao 10 .

Tabela 1 Lista de vídeos

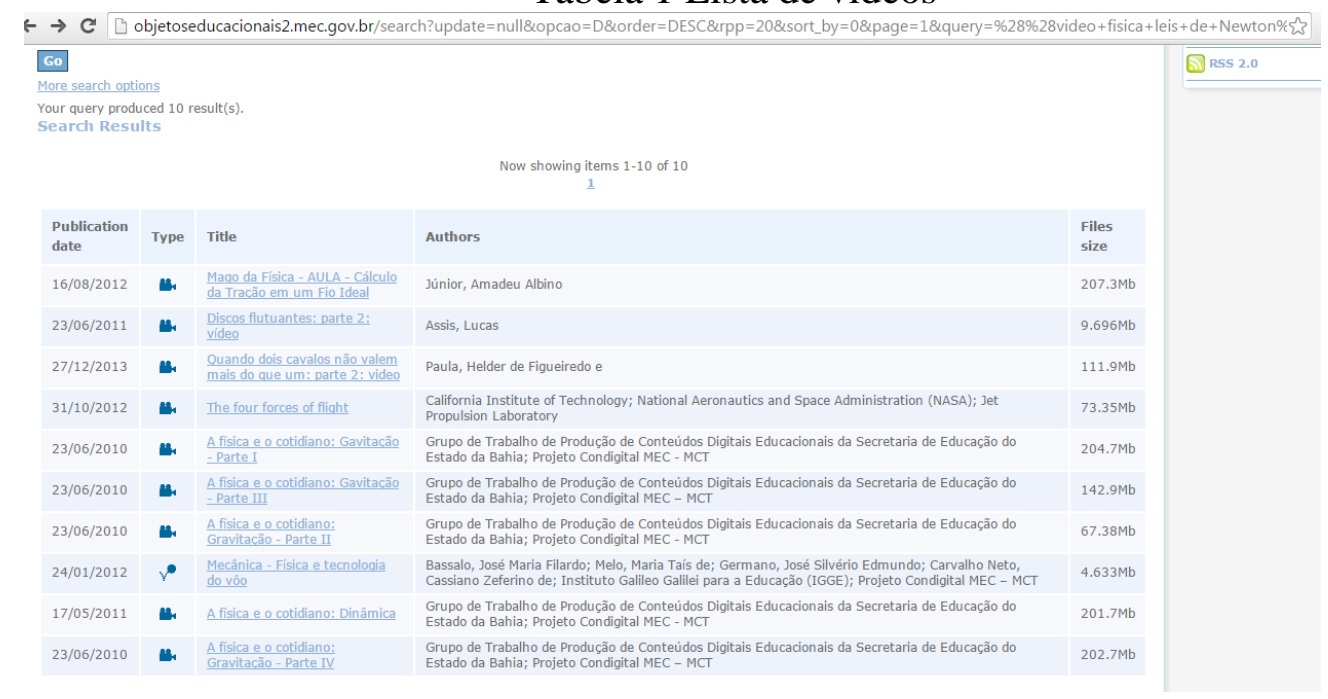

\subsection{Animação e/ou Simulação}

A Animação é uma construção voltada para uso de desenhos cuja organização produz o efeito de movimento. Simulação é a possibilidade de interagir com o objeto de forma a realizar uma experiência, no entanto sem ter os materiais reais. O aluno aprende sem estar no laboratório. Esse tipo de OA é muito útil no EAD pois apresenta uma situação de laboratório diretamente no AVA.

A busca com a opção "simulação + física” tem 927 animações/simulações para ensino médio, 702 para superior. Um refinamento na busca para "simulação+física+leis de Newton”

${ }^{2}$ http://objetoseducacionais2.mec.gov.br/search?query=videos+fisica

V. $14 \mathrm{~N}^{\circ} 2$, dezembro, 2016 
apresenta resultado de uma página com 9 itens, ver tabela 2, essas simulações serão numeradas de 11 ao 19.

Tabela 2. Lista de simulações/animações.

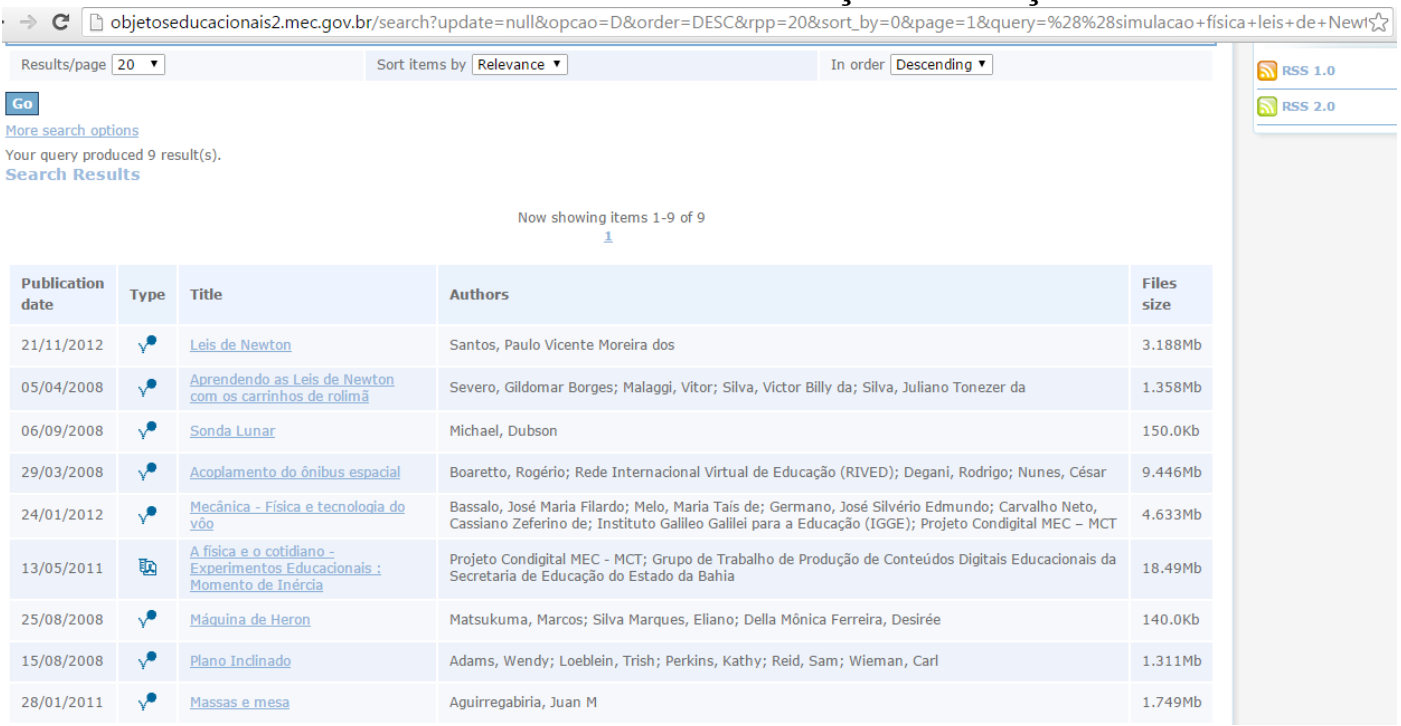

Os OA encontrados no site do MEC, possuem pontos fortes e fracos, relacionados com conteúdo e usabilidade com auxílio do professor, em relação a sua utilização em EAD e/ou ensino presencial. O material de vídeo (3), (4) e (9) se mostraram adequados para uso por aluno com surdez, o (1), (5), (6), (7) e (10) não são adequados. As animações (8), (11) e (14) podem ser utilizadas por alunos surdos sem auxílio do professor. Os itens (2), (12) e (17) ao (19) podem parcialmente se utilizar em contexto de inclusão. O item (13) é um jogo em inglês no qual não foi encontrada uma opção de uso em AVA. (15) eliminado por duplicidade $(15)=(8)$ e (16) precisa de instalação e/ou atualização de software.

De acordo ao checklist apresentado na seção anterior, qualitativamente os OA não presentam interdisciplinaridade, a maioria não apresentam ambiente criativo, os vídeos não são interativos, as animações apresentam interação. Nenhum dos OA foi focalizado originalmente para ter acessibilidade (ex: Legendas ou Sinalização para uma pessoa surda) (Tabela 3).

Tabela 3 Conceitos relacionados com os OA.

\begin{tabular}{|l|l|l|}
\hline Conceito analisado & Videos & Animação/simulação \\
\hline Interdisciplinaridade. & Não & Não \\
\hline Ambiente criativo. & Não & Parcialmente \\
\hline Interatividade & Não & Sim \\
\hline Acessibilidade (ex Legenda) & $3 / 9(33 \%)$ & $3 / 8(37 \%)$ \\
\hline Fácil instalação/atualização & Sim & Não \\
\hline
\end{tabular}

Da analise de amostragem realizada dos $\mathrm{N}=19$ itens apresentados pela pesquisa no link, (o (16) foi eliminado por necessidade de atualização do software especifico e o (15) por duplicidade) onde $\mathrm{N}$ é o tamanho da população, foram analisados 17 do resultado. Esse valor corresponde a um erro amostral de $\mathrm{E}=7 \%$ obtido de $\mathrm{E}=0.07, \mathrm{n}_{0}=1 /(\mathrm{E})^{2}=204$, este valor do tamanho da amostra pode ser corrigido por se tratar de uma amostra pequena, a correção para o tamanho da amostra é dada por 


$$
\mathrm{n}=\mathrm{n}_{0} \times \mathrm{N} /\left(\mathrm{N}+\mathrm{n}_{0}\right)
$$

onde a equação (1) é o tamanho da amostra corrigido o que resulta em $\mathrm{n}=17,3$ aproximadamente, finalmente o tamanho será $n=17$.

Esta analise mostra que dos 17 itens, 6 deles podem ser utilizados em contexto de inclusão sem precisar acrescentar recursos, esses também podem ser utilizados para estudos autônomos. Isso representa um 35\% aproximadamente o que é pouco inclusive para uso por todos os alunos, já que o restante $65 \%$ precisa auxílio de um professor para contextualizar

\section{Considerações Finais}

Neste trabalho é realizado uma contextualização dos OA no marco da teoria de aprendizagem significativa crítica. São apresentados os conceitos vinculados com a modelização na física e seu proposito fundamental do modelo que é a interação do estudante com o mesmo para ter uma relação com o conhecimento e poder refletir e voltar a interagir. A partir dos conceitos de interação e interatividade é proposto a necessidade de uma incorporação aos objetos de acessibilidade para uso por pessoas surdas, como por exemplo a incorporação de legendas em LIBRAS ou português nos vídeos.

Os OA foram escolhidos do site do MEC e foi realizado um recorte das Leis de Newton após o qual cada um foi utilizado para avaliar se atingiam os parâmetros do checklist. Nenhum dos OA foi pensado para acessibilidade. Os vídeos não oferecem uma opção diversa de uma aula que poderia ser ministrada por um professor presencial além de um deles estar totalmente em inglês o que restringe seu uso no EAD e outras situações, como ensino presencial ou estudos individuais. As animações são interativas mas precisam do auxilio de professor. Podem ser utilizados como organizadores prévios para o conteúdo que será apresentado por possuir características do cotidiano do aluno. No entanto devem ser dadas as condições para que aconteça a aprendizagem significativa.

\section{Referências Bibliográficas}

ARANTES, A. R., et al, Objetos de aprendizagem no ensino de física, Física na Escola, v. 11, n. 1,2010

ARAUJO I. S. E VEIT, E. A., Interatividade em recursos computacionais aplicados ao ensino-aprendizagem de físical, Anais da $14^{\mathrm{a}}$ Jornada Nacional de Educação. Santa Maria : Editora da Unifra, 2008.

em junho 2016

, 2009 disponivel em http://www.if.ufrgs.br/cref/uab/midias/aula01.html acesso

, Veit, E. A., Moreira, M. A., Modelos computacionais no ensino aprendizagem de física: um referencial de trabalho, Investigações em Ensino de Ciências - V17(2), pp. 341-366, 2012

BARDY, L. R. et al, Objetos de aprendizagem como recurso pedagógico, Rev. Bras. Ed. Esp., Marília, v. 19, n.2, p. 273-288, Abr.-Jun., 2013 
, L. R. et al, Os objetos de aprendizagem para Pessoas com Deficiência (PD) in Objetos de aprendizagem: uma proposta de recurso pedagógico. Organização: Carmem Lúcia Prata, Anna Christina Aun de Azevedo Nascimento. - Brasília : MEC, SEED, 2007.154 p. ISBN: 978-85-296-0093-2

KOHL de OLIVEIRA, Marta, VYGOTSKY, aprendizado e desenvolvimento um processo sócio-histórico Ed. Scipione 3ra edição, 1995.

LIMA, P. A., Educação Inclusiva e igualdade Social, Ed. Avercamp 2a reimpressão, 2010.

MEC, 2016 disponivel em http://objetoseducacionais2.mec.gov.br/ acesso em junho 2016

MOREIRA, M.A, Aprendizagem Significativa Crítica, Versão revisada e estendida de conferência proferida no III Encontro Internacional sobre Aprendizagem Significativa, Lisboa (Peniche), 11 a 15 de setembro de 2000. Publicada nas Atas desse Encontro, pp. 3345, com o título original de Aprendizagem significativa subversiva. Publicada também em Indivisa, Boletín de Estúdios e Investigación, $\mathrm{n}^{\circ}$ 6, pp. 83-101, 2005, com o título Aprendizaje Significativo Crítico. $1^{a}$ edição, em formato de livro, 2005; $2^{a}$ edição 2010; ISBN 85-904420$7-1$.

Phet - Colorado, Pesquisas de acessibilidade, 2015https://phet.colorado.edu/pt_BR/accessibility/research Acesso em julho 2016

PRIMO, A. F. T. e CASSOL, M. B. T., Explorando o conceito de interatividade: definiçõos e taxonomias, 1999 http://seer.ufrgs.br/InfEducTeoriaPratica/article/view/6286 acesso em julho 2016

SANTAELLA, L., "Linguagens liquidas na era da mobilidade”, Ed Paulus, 2007, pg 189

SILVA, L.F., et al, Realidade Virtual e Ferramentas Cognitivas Usadas como Auxílio para o Ensino de Física, Novas Tecnologias na Educação CINTED-UFRGS, V. 6 No 1, Julho, 2008

VALENTE, J.A. Liberando a mente: computadores na educação especial. Campinas: Gráfica Central da Unicamp, 1991. Citado em BARDY, L. R. et al, Objetos de aprendizagem como recurso pedagógico, Rev. Bras. Ed. Esp., Marília, v. 19, n.2, p. 273-288, Abr.-Jun., 2013

VERASZTO, et al, Educação a distância e estilos de aprendizagem: estratégicas educativas apoiadas pelas tic, cap 12 in Estilos de Aprendizagem na Atualidade: volume 1. ISBN: 978989-97467-0-1 MODO DE ACESSO DISPONÍVEL EM: http://estilosdeaprendizagemvol01.blogspot.com/

WINCMAP TOOLS, v6.01.01, Institute for Human and Machine Cognition, http://cmap.ihmc.us/ , acesso maio, 2016 